\title{
RANDOMIZED CONTROLLED TRIAL OF LIGASURE VESSEL SEALING SYSTEM VERSUS CONVENTIONAL SUTURE LIGATURE FOR TOTAL ABDOMINAL HYSTERECTOMY
}

\author{
Radhika Pooli', G. Sravanthi², M. Tripura Sundari ${ }^{3}$ \\ ${ }_{1}^{1}$ Assistant Professor, Department of Obstetrics \& Gynaecology, Gandhi Medical College, Secunderabad. \\ ${ }^{2}$ Assistant Professor, Department of Obstetrics \& Gynaecology, Gandhi Medical College, Secunderabad. \\ ${ }^{3}$ Retd-Professor, Department of Obstetrics \& Gynaecology, Gandhi Medical College, Secunderabad.
}

\begin{abstract}
AIM

To compare the use of LigaSure with conventional suture ligation in total abdominal hysterectomy.

\section{MATERIALS AND METHODS}

Fifty patients undergoing total abdominal hysterectomy over a period of 3 years were randomized to either LigaSure or sutures as the haemostatic technique at Gandhi Medical College and Hospital, Secunderabad. The parameters evaluated and compared between the two groups include operation time, intraoperative blood loss, need for blood transfusion, intraoperative and postoperative complications. The mean value for blood loss, hemoglobin drop and procedure time were compared with T test. Level of significance was considered as 0.05 . Chi square test was used to study the association between groups and intraoperative and postoperative complications.
\end{abstract}

\section{RESULTS}

Statistically significant time saving effect was observed with P value of 0.014 with LigaSure in comparison with suture ligation (48.0 mins vs $60.3 \mathrm{mins}$ ). In the LigaSure arm blood loss was significantly less with decreased intraoperative blood transfusion. Intraoperative bleeding due to slippage of ligated uterine artery occurred in one case in suture ligation arm. Postoperative pain reflected by increased dose of analgesics was more in suture ligation arm.

\section{CONCLUSION}

Use of LigaSure is an effective haemostatic seal in reducing operating time. It allows faster, safe and effective haemostasis compared to conventional suture ligation in total abdominal hysterectomy. It also reduces operative blood loss, post-operative pain, hospital stay and risk of needle prick injuries. It provides translucent seal, resists dislodgement and increases surgeon's confidence.

\section{KEYWORDS}

Ligasure Vessel Sealing System, Conventional Sutures, Blood Loss, Total Abdominal Hysterectomy.

HOW TO CITE THIS ARTICLE: Pooli R, Sravanthi G, Sundari MT. "Randomized controlled trial of Ligasure vessel sealing system versus conventional suture ligature for total abdominal hysterectomy." Journal of Evolution of Medical and Dental Sciences 2015; Vol. 4, Issue 103, December 24; Page: 16835-16837, DOI: 10.14260/jemds/2015/2528

\section{INTRODUCTION}

Hysterectomy is one of the most frequently performed surgery worldwide.(1) The rapid, safe and complete sealing of vessels is an important part of a successful total abdominal hysterectomy. Achieving haemostasis is fundamental in all surgical approaches. Traditionally, several methods have been used such as clips, staples, sutures, ultrasonic and monopolar or bipolar coagulation. Among these the LigaSure vessel sealing system, effectively seals vessels.(2) LigaSure technology delivers a unique combination of pressure and energy to create a consistent seal with each application, especially in sealing medium size vessels. The use of LigaSure has been critically assessed for range of procedures such as haemorrhoidectomy, splenectomy, thyroidectomy, bile duct, urological and gastric operations. $(2,3,4)$ The present study is a prospective randomised controlled trial done over a period of 3years in 50patients undergoing total abdominal hysterectomy in the Department of Obstetrics and Gynaecology.

Financial or Other, Competing Interest: None.

Submission 05-12-2015, Peer Review 07-12-2015,

Acceptance 18-12-2015, Published 23-12-2015.

Corresponding Author:

Dr. Radhika Pooli,

H. No. 4-7-12/53, Ravindra Nagar Colony,

Nacharam, Hyderabad-500076,

Telangana.

E-mail: radhikapooli@yahoo.co.in

DOI:10.14260/jemds/2015/2528
Gandhi Medical College and Hospital, Secunderabad, India. The 50 patients were randomised into two groups with 25 each, which include total abdominal hysterectomy using traditional suturing technique in one group and LigaSure vessel sealing system in the other. The emphasis of this study was done to note the safety and efficacy of LigaSure with respect to intraoperative blood loss, operative time, requirement of suture material, operative complications and post-operative morbidity.

\section{MATERIALS AND METHODS}

The present study was a prospective trial conducted over a period of 3 years. Study approval was obtained from our local department Research Ethics Committee. The patients who were to undergo elective total abdominal hysterectomy were randomised into two groups with 25 each. Randomisation was performed using a list of computer generated random numbers. The first group include patients undergoing total abdominal hysterectomy using traditional suturing techniques. The second group constitute patients where LigaSure was used during total abdominal hysterectomy.

The operations were performed by experienced surgeons. The operating surgeons were informed of the method to use just before the start of surgery and this information did not influence, which surgeon was to operate. The patients were blinded to treatment method. Informed and written consent was taken from enrolled patients. Antibiotics which include 500mg metronidazole and 1 gram ceftriaxone were given one hour before the start of surgery. All operations 
were performed under general anaesthesia in the lithotomy position. The LigaSure device used is a precise open instrument (LS1200) - A curved jaw vessel sealing instrument that provides fine grasping and effectively dissects tissue planes in open procedures. The device consists of a bipolar radiofrequency generator, a reusable hand-piece and disposable electrodes. The generator delivers a low voltage high power current.

The age of the patients in both the groups range from 25 to 65 years. The indication for surgery in all the 50 patients was dysfunctional uterine bleeding and patients with gynaecological malignancy, uterine myomas and genital prolapse. Patients with uncontrolled medical condition and coagulation disorder were also excluded from the study.

Each patient in the study were tested for the following parameters. These include operative time, number of sutures required, operative blood loss and the need for blood transfusions, post-operative pain assessment, hospital stay and post-operative complications. The operative time was defined as the time from the beginning of the procedure till its completion. The average number of suture requirement for both the groups were compared. The operative blood loss and the need for blood transfusion were noted by assessing the blood soaked towels, swabs, blood collected in suction bottles and by comparing the pre- and post-operative haematocrit. The post-operative pain was assessed by pain score system and the need for analgesic medication.

The number of days as inpatient following surgery were noted in both the groups. The postoperative morbidity during immediate period like fever, wound sepsis, urinary retention following catheter removal and gastrointestinal symptoms were noted. The late postoperative complications like vault granulation, chronic pelvic pain, atonic bladder and dyspareunia were also noted. The mean value for blood loss haemoglobin drop and procedure time were compared with T test. Level of significance was considered as 0.05 . Chi square test was used to study the association between groups and intraoperative complications.

\section{RESULTS}

The index study enrolled 50 patients with dysfunctional controlled bleeding with comparative analysis of parameters of total abdominal hysterectomy, patients with and without use of LigaSure.

Table 1 provides comparative analysis of operative blood loss. The mean blood loss was lesser in LigaSure group, i.e. $68.9 \mathrm{ml}$ as compared to $126.7 \mathrm{ml}$ in conventional suture ligation group, which is statistically significant (P. value of freedom0.05).

\begin{tabular}{|c|c|c|c|}
\hline ANALYSIS & LIGASURE & $\begin{array}{c}\text { SUTURE } \\
\text { LIGATION }\end{array}$ & $\begin{array}{c}\text { P- } \\
\text { Value }\end{array}$ \\
\hline $\begin{array}{c}\text { Average blood } \\
\text { loss }\end{array}$ & $68.9 \mathrm{ml}$ & $126.7 \mathrm{ml}$ & 0.005 \\
\hline $\begin{array}{c}\text { Average } \mathrm{Hb} \\
\text { drop }\end{array}$ & $1.65 \mathrm{gm} \%$ & $2.3 \mathrm{gm} \%$ & 0.725 \\
\hline \multicolumn{2}{|c|}{ Table 1: Analysis based on intraoperative Blood Loss } \\
\hline
\end{tabular}

Table 2 shows analysis based on procedure time and number of sutures used. The average operative time was shorter in LigaSure group, i.e. 48 mins as compared to 60.3 mins in conventional suture ligation group, which is statistically significant with a P value 0.014 .

The number of sutures required was found to be an average of 5.8 sutures in LigaSure group and 24.20 sutures in conventional suture ligation group.

\begin{tabular}{|c|c|c|c|}
\hline Analysis & LigaSure & $\begin{array}{c}\text { Suture } \\
\text { Ligation }\end{array}$ & $\begin{array}{c}\text { P- } \\
\text { value }\end{array}$ \\
\hline $\begin{array}{c}\text { Average procedure } \\
\text { time }\end{array}$ & $48.0 \mathrm{~min}$ & $60.3 \mathrm{~min}$ & 0.014 \\
\hline $\begin{array}{c}\text { Average No. of } \\
\text { sutures }\end{array}$ & 5.4 & 22.23 & \\
\hline Table 2: Analysis based on procedure time and No. of \\
sutures
\end{tabular}

Table 3 provides the comparison of intraoperative complication; intraoperative complications like haemorrhage, requirement for blood transfusions, bladder injuries and needle prick injuries were more in conventional suture ligation group as compared to LigaSure group. The average perioperative drop in $\mathrm{HB} \%$ was $1.65 \mathrm{gm} \%$ with LigaSure and $2.3 \mathrm{gm} \%$ in conventional suture ligature group, which is statistically significant $(\mathrm{P}$ value $=0.725)$.

\begin{tabular}{|c|c|c|}
\hline $\begin{array}{c}\text { Intraoperative } \\
\text { Complications }\end{array}$ & LigaSure & Suture Ligation \\
\hline Haemorrhage & $1(4 \%)$ & $5(20 \%)$ \\
\hline Blood transfusion & $2(8 \%)$ & $8(32 \%)$ \\
\hline Needle pricks & $0(0 \%)$ & $2(8 \%)$ \\
\hline Bladder injury & $0(0 \%)$ & $2(8 \%)$ \\
\hline \multicolumn{2}{|c|}{ Table 3: Analysis based upon intraoperative } \\
complications \\
\hline
\end{tabular}

The comparative study of post-operative complications of with and without use of LigaSure during total abdominal hysterectomy is provided in Table 4. Postoperative pain and the need for frequent dose of analgesics was slightly more in suture ligation group as compared with LigaSure. Bladder Symptoms were noted in $23.3 \%$ in suture ligation group, whereas in $10 \%$ of cases in LigaSure group. Incidence of wound sepsis was almost same in both the groups. Febrile morbidity, i.e. temperatures more than $38^{\circ} \mathrm{C}$ was seen in $16 \%$ of LigaSure cases as compared to $16.6 \%$ in Conventional Suture group.

\begin{tabular}{|c|c|c|}
\hline $\begin{array}{l}\text { Post-operative } \\
\text { Complications } \\
\end{array}$ & LigaSure & $\begin{array}{c}\text { Suture } \\
\text { Ligation }\end{array}$ \\
\hline $\begin{array}{c}\text { Continuous bladder } \\
\text { drainage }\end{array}$ & $5(20 \%)$ & $4(16 \%)$ \\
\hline Wound sepsis & $3(12 \%)$ & $2(8 \%)$ \\
\hline G.I. effects & $4(16 \%)$ & $2(8 \%)$ \\
\hline Febrile morbidity & $4(16 \%)$ & $5(20 \%)$ \\
\hline
\end{tabular}

Table 5 shows the comparative analysis of the late complications of the both groups

Remote complications like vault granulation, chronic pelvic pain, atonic bladder and dyspareunia are slightly more in conventional suture ligation group.

\begin{tabular}{|c|c|c|}
\hline $\begin{array}{c}\text { Remote } \\
\text { Complications }\end{array}$ & LigaSure & Suture Ligation \\
\hline Vault granulation & $1(4 \%)$ & $1(4 \%)$ \\
\hline Chronic pelvic pain & $3(12 \%)$ & $5(20 \%)$ \\
\hline Atonic bladder & $0(0 \%)$ & $1(4 \%)$ \\
\hline Dyspareunia & $1(4 \%)$ & $0(0 \%)$ \\
\hline
\end{tabular}

\section{DISCUSSION}

The present study was conducted to evaluate the efficacy of LigaSure in securing vascular pedicles in Total Abdominal Hysterectomy by comparing the intraoperative and postoperative complications with that of conventional suture ligation. 
A statistical significant time saving effect was observed (P. value of 0.014) with LigaSure seal in comparison to sutures. In a similar randomized controlled trial conducted by Aydin C et al.(5) observed that the LigaSure device significantly reduced the operation time $(\mathrm{p}<0.05)$. The study conducted by Hefni M.A. et al.(6) also showed similar findings where the mean optimum time is $57 \mathrm{~min}$ a randomized controlled trial compared to control group, which was $66 \mathrm{~min}$. Robert McLellan et al. had shown significant time saving with LigaSure in comparison to sutures in total abdominal hysterectomy.(7) On the contrary, Bjorn Hagen, et al. in their trial showed that the mean operative duration was longer and blood loss was more with LigaSure than suture ligation. ${ }^{(8)}$ This difference in favour of suture ligation, however, did not reach statistical significance and the study sample is small, which include 30 subjects.

In the present trial, the number of sutures required to ligate the pedicles in order to achieve haemostasis was found to be an average of 5.4 extra sutures in LigaSure group and 22.23 sutures in suture ligation group, which was statistically significant with a P-value of 0.014 . The extra sutures were applied to vascular pedicles in LigaSure group only during the initial stage of the study for the first five cases and in another 20 patients the procedures were done solely with ligature vessel sealing system. Dr. Raffaele Bruno of Lahey Clinic Burlington, in their study applied an average of 5 sutures in LigaSure group and 17 sutures in conventional suture ligation group. ${ }^{(9)}$

The mean blood loss was lesser in bipolar vessel ligation group, i.e. $68.9 \mathrm{ml}$ which was statistically significant with (Pvalue of freedom -0.05). Similar results were observed by Dr. Raffaele Bruno of Lahey Clinic, Burlington where the blood was $74.2 \mathrm{ml}$ in bipolar vessel sealer group compared to $118.7 \mathrm{ml}$ in conventional suture ligation group.(9) Another study done by Hefni, M.A. et al. of Beneden Hospital where blood loss was $110 \mathrm{ml}$ in LigaSure compared to $161 \mathrm{ml}$ in suture ligation.(6) The major advantages of reducing intraoperative blood loss are minimizing the requirement of blood transfusions and hence reducing the risk of transfusion related complications. Dry operative field promotes accurate identification and dissection of structures thus reducing trauma to surrounding tissues by blind clamping. It improves precision of surgery.

Intraoperative complications like haemorrhage due to sudden slippage of ligature occurred in one case in conventional suture ligation group, whereas no such complications happened in LigaSure group. The results showed by Hefni M.A. et al. of Beneden Hospital, UK for perioperative haemorrhage is $0 / 57$ in Ligasure group and $4 / 57$ in suture ligation group due to unsecured pedicles.(6)

In the present study, the number of intraoperative blood transfusions needed were lesser in LigaSure group (6.6\%) as compared to suture ligation group $(23.3 \%)$. Dr. Tamussino et al. of The Medical University of Graz, Austria, also showed that in his study fewer packed RBC transfusions were required for LigaSure group as against the conventional clamps.(10)

The average perioperative haemoglobin percentage drop in the present study was $1.65 \mathrm{gm} \%$ with LigaSure group, which is quite lesser than in the suture ligation group where there was a drop of $2.3 \mathrm{gm} \%$. (P-value $=0.725$ ) which is statistically significant. Hefni M.A. et al. of Beneden Hospital showed a reduction of haemoglobin of $1.2 \mathrm{gm} \%$ in LigaSure group and $1.5 \mathrm{gm} \%$ in conventional suture ligation group. ${ }^{(6)}$

The need for frequent dose of post-operative analgesics was slightly more in conventional suture ligation group as compared with LigaSure. The cause of increased pain in conventional suture ligation group may be due to the inflammatory response initiated by increased operative time, tissue handling and tissue reaction caused by the suture material.

Prolonged bladder drainage was required in $23.3 \%$ of the cases in conventional suture ligation group, which was mostly due to the dissection done for separation of adherent bladder in cases of previous LSCS in comparison to $10 \%$ of cases in LigaSure.

Vault granulation were noted one in each group, which was treated with copper sulphate crystals. Wound sepsis was almost same in both the groups. Chronic pelvic pain, either continuous or intermittent were noted in $20 \%$ of the cases in conventional suture ligation group as compared to $12 \%$ of cases LigaSure group.

The limitation of this study is small sample size and further randomised studies are required to determine the long term effects of using LigaSure for total abdominal hysterectomy.

\section{CONCLUSION}

Use of LigaSure is an effective haemostatic seal in reducing operating time. It allows faster, safe and effective haemostasis compared to conventional suture ligation in total abdominal hysterectomy. It also reduces operative blood loss, postoperative pain, hospital stay and risk of needle prick injuries. It provides translucent seal, resists dislodgement and increases surgeon's confidence.

\section{REFERENCES}

1. Santiago Domingo, Antonio Pellicer. Overview of Current Trends in Hysterectomy. Expert Review of Obstetrics \& Gynecology 2009;4(6)

2. Bimal Kumar Sah, Jianjun Yang, Guantian Yang, et al. Clinical uses of LigaSure Vessel Sealing System (LVSS) in surgery. Journal of Nanjing Medical University 2008;22(2)

3. Anandi HW Schiphorst, Bas A Twigt, Sjoerd G Elias. Randomised clinical trial of LigaSure versus conventional suture ligation in thyroid surgery. Head and neck oncology 2012;4(2):

4. Palazzo FF, Francis DL, Clifton MA. Randomised clinical trial of LigaSure versus open haemorrhoidectomy. Br J Surg 2002;89

5. Aydin C, Yildiz A, Kasap B, Yetimalar H, Kucuk I, Soylu F. Efficacy of electrosurgical bipolar vessel sealing for abdominal hysterectomy with uterine myomas more than 14 weeks in size: a randomized controlled trial. Gynecol Obstet Invest 2012;73(4):326-9.

6. Hefni MA, Bhaumik J, El-Toukhy T, Kho P, Wong I, AbdelRazik T, et al. (2005). Safety and efficacy of using the LigaSure vessel sealing system for securing the pedicles in vaginal hysterectomy: randomised controlled trial. BJOG: An International Journal of Obstetrics \& Gynaecology 112:329-333.

7. Robert McLellan, Carol Anania, Melinda Birdsall, et al. LigaSure versus sutures in total abdominal hysterectomy. Obstetrics \& Gynecology 2001;97(4)

8. Hagen B, Eriksson N and Sundset M (2005). Randomised control trial of LigaSure versus conventional suture ligature for abdominal hysterectomy. BJOG: An International Journal of Obstetrics \& Gynaecology 112:968-970.

9. Bruno D. Innovations stem blood loss in hysterectomy Free Online Library [Internet]. The free library.com. 2015 [cited 4 December 2015].

10. Tamussino K1, Afschar P, Reuss J, Perschler M, Ralph G, Winter R. Electrosurgical bipolar vessel sealing for radical abdominal hysterectomy. Gynecol Oncol 2005 Feb;96(2). 